\title{
Oxygen Exposure in the Newborn Guinea Pig Lung Lavage Cell Populations, Chemotactic and Elastase Response: a Possible Relationship to Neonatal Bronchopulmonary Dysplasia
}

\author{
T. ALLEN MERRITT ${ }^{(30)}$ \\ Department of Pediatrics, Division of Neonatal/Perinatal Medicine, University of California, \\ San Diego, California, USA
}

\section{Summary}

Neonatal guinea pig pulmonary response to oxygen exposure $\mathrm{FiO}_{2}>0.9$ resulted in an increase in total cell number in lung lavage. Alveolar macrophages initially increased within 48 h of exposure. Polymorphonuclear leukocytes and macrophages exceeded age-matched neonatal control values by $72 \mathrm{~h}$ of oxygen exposure. By $144 \mathrm{~h}$ of life, total inflammatory cell number still exceeded control cell populations. Chemotaxis of alveolar macrophages to $\mathrm{N}$-formyl-methionyl-phenylalanine $\left(1 \times 10^{-5} \mathrm{M}\right) \mathrm{ex}$ ceeded chemotaxis of air-exposed controls. Although initially depressed, by $72 \mathrm{~h}$ of $\mathrm{Fio}_{2}>0.9$ polymorphonuclear leukocyte chemotaxis increased 6-fold. Endogenous chemotactic peptides were demonstrated in lung lavage supernatant of oxygen-exposed neonatal guinea pigs. Elastase activity rose in oxygen exposed guinea pigs by 72 h of life. Lung lavage disaturated phosphatidylcholine in oxygen-exposed neonates exceeded control values 4fold. In a preliminary study, lung effluent elastase activity was found to be increased in human neonates with respiratory distress syndrome over the first days of life compared to infants intubated but without lung disease. In infants developing bronchopulmonary dysplasia, tracheal aspirate protease activity remained greater than $10^{-3} \mathrm{U}$ for over 10 days and up to 5 weeks of age.

\section{Speculation}

Lung damage in neonatal guinea pigs from elevated oxygen exposure results in lung cell injury with enhanced chemotaxis for polymorphonuclear leukocytes and macrophages. These cells release proteolytic enzymes into pulmonary effluent. These proteolytic enzymes may, if unabated, result in lung connective tissue damage. Although previously described only in adult animals and implicated in the adult respiratory distress syndrome, similar processes may be operative in the development of neonatal bronchopulmonary dysplasia.

It is tempting to extrapolate our finding of higher amounts of elastase activity in tracheal effluent in infants developing bronchopulmonary dysplasia compared to other infants without lung disease or respiratory distress syndrome to similar findings in neonatal guinea pigs exposed to high concentrations of oxygen. Although this extrapolation may not be justified without further studies documenting the precise source of elastase activity, monitoring of lung effluent protease activity may provide useful biochemical indices of neonatal lung injury. Modulation and/or prevention of neonatal lung injury may be possible by reducing proteolytic activity either by reducing lung inflammation or increasing endogenous antiprotease activity.

The finding of inflammatory cell populations in tracheobronchial secretions of preterm and term neonates, who require mechanical ventilation with elevated concentrations of inspired ox- ygen because of ventilatory failure $(24,25)$, prompted an evaluation of the response of the neonatal lung to high levels and durations of oxygen therapy. Furthermore, many preterm infants, who require prolonged mechanical ventilation because of ventilatory failure owing to surfactant deficiency and neonatal respiratory distress syndrome, develop chronic pulmonary disease with pathologic characteristics suggestive of oxygen toxicity in combination with mechanical ventilation termed bronchopulmonary dysplasia (26). Although it has not been possible to factor out the effects of high oxygen exposure, the influence of mechanical ventilation, the influence of lung immaturity, or a combination of the above factors, similar cellular changes have been reported in adult animals exposed to high oxygen levels. Studies of neonatal lung responsiveness to oxygen injury remain incomplete. The objective of this study was to elucidate the nature of cellular inflammatory response in the neonatal guinea pig lung and to determine whether elaboration of proteolytic enzymes into pulmonary effluent occurs in the immature or neonatal animal in a sequence similar to that found in adult animals and man. Both the chemotactic behavior of adult pulmonary inflammatory cells and their release of proteolytic enzymes injurious to lung tissue have been reported in adult respiratory distress syndrome (19), yet to our knowledge similar studies have not been reported in the neonatal animal or human infant.

Since bronchoalveolar lavage techniques used in adult studies are not possible in critically ill human neonates, we chose to use the neonatal guinea pig for our investigations of lung inflammatory cell response. We chose, however, to determine elastase levels in both neonatal guinea pig lung effluent exposed to air and oxygen and sequentially in human neonatal tracheal aspirates.

Northway and coworkers (27) previously reported radiographic and histologic features in neonatal guinea pigs exposed to oxygen of $\mathrm{FiO}_{2}>0.9$ for up to 6.5 days to be nearly identical to those they initially described in human neonates with bronchopulmonary dysplasia (4). Furthermore, adult guinea pig inflammatory cell directed migration and elastase determination in lung bronchoalveolar lavage has previously been reported for comparison to neonatal values $(7,8,20)$.

We further measured lung effluent elastase levels from intubated human neonates requiring mechanical ventilation using endotracheal tubes for ventilatory failure or because the infants underwent surgical procedures requiring muscle relaxation and extended ventilation. The latter studies, though preliminary, indicate that oxygen exposure in human newborns may result in a similar pattern of pulmonary injury as demonstrated in the neonatal guinea pig. This evidence of lung injury may be the initiating event in the genesis of bronchopulmonary dysplasia.

\section{MATERIALS AND METHODS}

Consent. The collection of human neonatal lung effluent obtained during routine tracheobronchial aspiration in infants was 
approved by the School of Medicine Committee for the Protection of Human Subjects.

Animals. Timed pregnant Hartley strain guinea pigs (Charles River, Cambridge, MA) were employed in these studies. The pregnant dams were observed every $4 \mathrm{~h}$ during the latter days of pregnancy for delivery of pups. Within $4 \mathrm{~h}$ after spontaneous delivery, the dams and pups were placed in a 20-liter environmental chamber (Merritt Machine Co., Wichita, KS) with controlled ambient $\mathrm{FiO}_{2}, \mathrm{FiCO}_{2}$, temperature, and humidity. The oxygen or air entering the chamber was filtered through 5 layers of $1 \mu \mathrm{m}$ pore filter paper. $\mathrm{FiO}_{2}$ was analyzed every $4 \mathrm{~h}$ (Ventronics Oxygen Analyzer, Temecula, CA) and $\mathrm{FiCO}_{2}$ was always less than 0.01 (Beckman $\mathrm{CO}_{2}$ Analyzer, Schilla Park, IL). This chamber permitted exchanging dams every $24 \mathrm{~h}$ from room air to $\mathrm{FiO}_{2}>0.9$ in less than $15 \mathrm{sec}$ and permitted chow, water and litter changes without altering ambient oxygen levels. Guinea pig pups exposed to an $\mathrm{FiO}_{2}>0.9$ were cross-fostered with dams exposed to $\mathrm{FiO}_{2}$ $=0.21$ at 24 hourly intervals and all animals were observed to nurse.

Collection of pulmonary effluent and cells. After intraperitoneal pentabarbital for anesthesia, a tracheostomy was performed and five lung washes using $20 \mathrm{ml}$ each of calcium free Gey's Balanced Salt Solution (GBSS) at $4^{\circ} \mathrm{C}$ was performed. Lung lavage fluid was centrifuged at $500 \times \mathrm{g}$ for $15 \mathrm{~min}$ at $4^{\circ} \mathrm{C}$ and the cell free supernatant removed for subsequent analysis. The cell pellet was resuspended in $10 \mathrm{ml}$ of GBSS and centrifuged as before. The supernatant was decanted from the cellular pellet and the cells resuspended for $30 \mathrm{sec}$ in $20 \mathrm{ml}$ of $0.2 \mathrm{M} \mathrm{NaCl}$ to osmotically lyse erythrocytes. Isotonicity was restored by adding $20 \mathrm{ml}$ of $1.6 \mathrm{M}$ $\mathrm{NaCl}$ and this volume centrifuged as initially described. To the residual cell pellet, $10 \mathrm{ml}$ GBSS with $2 \%$ fatty acid free bovine serum albumin (BSA) (Sigma Chemical Corp., St. Louis, MO) $(\mathrm{pH}=7.4)$ was added. Cell viability was determined by trypan blue exclusion and consistently exceeded $90 \%$. Total cell counts were performed on cell preparations stained with Diff-Quik (Harleco, Philadelphia, PA). Ten differential cell counts were averaged and the mean \pm 1 S.D. determined for each animal exposed to either condition for macrophages, neutrophilic polymorphonuclear leukocytes (PMNs), and "other," primarily monocytes.

Chemotactic assays. The chemotactic response in pulmonary macrophages and PMNs to $1 \times 10^{-5} \mathrm{M} \mathrm{N}$-formyl-methionylphenylalanine (Sigma Chemical Co., St. Louis, MO) and to lung lavage supernatant was determined using a modification of the technique described by Dauber and Daniele (8).

Because oxygen exposure to various durations of $\mathrm{FiO}_{2}>0.9$ yielded highly different cell populations in terms of absolute cell number and cell type, we chose not to determine absolute cell numbers migrating through the filter. Rather, we derived a chemotactic index based upon the number and type of cells migrating through a filter versus those adhering to the surface of the upper filter, formulating a chemotactic index. Briefly, $200 \mu \mathrm{l}$ of fluid containing either the chemotaxin diluted in GBSS and $2 \%$ fatty acid free BSA or pulmonary effluent was injected into the lower compartment of a sterile $4.7-\mathrm{mm}$ blind well chemotactic chamber (Neuroprobe, Bethesda, MD). Two hundred $\mu$ of the responding cell suspensions at varying cell concentrations in GBSS plus $2 \%$ fatty acid free BSA was placed in the upper compartment. Between the compartments a $5-\mu \mathrm{m}$ pore polycarbonate filter (Nucleopore Corp., Pleasanton, CA) was superimposed upon a $0.2-\mu \mathrm{m}$ pore polycarbonate filter (Schleicher and Schuell, Keene, NH) in order to permit directed migration through the upper filter but to impede diapedesis through the lower filter. The chambers were incubated in humidified air at $37^{\circ} \mathrm{C}$ for 90 min after which the filters were removed, dried, and stained with Diff-Quik, and mounted in Permamount (Fisher Scientific Co., Fair Lawn, NJ) on glass slides. Chemotactic response for each cell type to $1 \times 10^{-5} \mathrm{M} \mathrm{N}$-formylmethionyl-phenylalanine or lung effluent was quantified by counting the number of cells migrating through the upper filter divided by the number of cells of the same type remaining at the surface of the $5-\mu \mathrm{m}$ filter in 20 adjacent oil immersion fields with an ocular grid per slide per each animal exposed to air or varying durations of $\mathrm{FiO}_{2}>0.9$. The chemotactic index representing the

\section{CHEMOTACTIC INDEX =}

Cells Chemotactic Thru
$5 \mu$ Filter to $1 \times 10^{-5}$ M FMP
$\begin{aligned} & \text { Cells Remaining on } 5 \mu \text { Filter } \\ & \text { in GBSS }+2 \% \text { BSA }\end{aligned}$

Fig. 1. Calculation of the chemotactic index. Cells migrating through the $5-\mu \mathrm{m}$ filter towards the chemotactic agent divided by the cells remaining on the surface of the $5-\mu \mathrm{m}$ filter $\times 100$ was termed "chemotactic index." This index was necessary because of the variable cell populations.

mean \pm 1 S.D. of this quotient $\times 100$ was calculated for each exposure condition (Fig. 1). To determine whether cellular adherence was different than the total cell population placed in the upper compartment of the chemotactic chamber, a differential cell count of the cells was made from $50 \mu \mathrm{l}$ of cell suspension and compared to the differential count of cells on the surface of the 5$\mu \mathrm{m}$ filter. To exclude random migration of lung effluent cells, responding cells were exposed to no stimulus in the lower well, uniform concentrations of chemotactic agents in both the upper and lower well to produce stimulated random migration, as well as to positive and negative gradients of $1 \times 10^{-5} \mathrm{M} \mathrm{N}$-formylmethionyl-phenylalanine or lung effluent supernatant to produce directed random migration.

Elastase assay. Fresh lung effluent elastase activity against succinyl-L-alanyl-L-alanyl-L-alanine- $p$-nitroanilide (Bachem, Marina Del Rey, CA) was measured in triplicate, as was a linear standard curve generated between 0.05 and $3 \mu \mathrm{g}$ using porcine pancreatic elastase (Type III) (Worthington, Freehold, NJ) according to the methods of Levine and coworkers (20) for each experimental condition, as well as, human newborn lung lavage supernatant in triplicate using similar techniques on $100 \mu \mathrm{l}$ of pulmonary effluent. Aliquots of effluent were incubated with 10 mM ethylene diamine tetraacetic acid (EDTA) (Sigma Chemical $\mathrm{Co}$, St. Louis, MO) or $10 \mathrm{mM}$ phenylmethyl-sulfonylfluoride (PMSF) (Calbiochem-Behring, La Jolla, CA) for $30 \mathrm{~min}$ at $37^{\circ} \mathrm{C}$ respectfully, to inhibit metalloelastase activity or serine protease activity (9) and then reacted with succinyl-L-alanyl-L-alanyl-Lalanine- $p$-nitroanilide. One unit of elastase activity equalled the absorbance at $410 \mathrm{~nm}$ after hydrolysis for $6 \mathrm{~h}$ at $37^{\circ} \mathrm{C}$ of the substrate by elastase divided by the molar extinction coefficient of the synthetic peptide. EDTA inhibited metalloelastolytic activity $(1,14,20)$ has been reported to reflect macrophage elastase activity while PMSF (12) inhibition of serine elastase activity reflects leukocyte derived enzyme. Elastase activity in human neonates was determined in clinically indicated serial aspirates of lung effluent, obtained during endotracheal intubation for mechanical ventilation, after instilling $1.0 \mathrm{ml}$ of $0.9 \% \mathrm{NaCl}$ usually in three separate aliquots for approximately $15 \mathrm{sec}$ each and aspirating lung effluent. Each aspirate was performed in a standard manner on all infants. Although it might be argued that individual pulmonary aspiration samples from these infants may not be constant owing to the differences in pulmonary disease (or lack of it), we were able to determine the recovery of pulmonary effluent by adding $25 \mathrm{mg} / \mathrm{dl}$ urea to the saline injected into the endotracheal tube to perform pulmonary toilet and by determining the urea concentration of the aspirated material using the following formula:

$$
\text { Vol lung }_{\text {lut }}=\text { Vol }_{\text {out }}-\frac{[\text { urea }]_{\text {out }}}{[\text { urea }]_{\text {in }}} \times \text { Total Vol in }
$$

where $\mathrm{Vol}_{\text {lung, }}$, aspirated fluid volume with origin in lung airways; $\mathrm{Vol}_{\text {out }}$, total volume returned by aspiration technique; [urea $]_{\text {out }}$, concentration of urea in aspirated fluid; [urea] $]_{i n}, 25 \mathrm{mg} / \mathrm{dl}$; and Total Vol in, the volume of saline and urea injected into the endotracheal tube for pulmonary toilet. Urea nitrogen concentration was measured by the Technicon Auto Analyzer (Terrytown, NY).

Phospholipid analysis. Lung lipids were extracted from lung lavage supernatant using the technique of Folch et al. (10). Ex- 
tracted lipids were separated using the solvent systems described by Hallman and coworkers (13) to separate lung surfactant phospholipids via two-dimensional thin layer chromatography on silica gel plates (Analtech, Newark, DE). Authentic phospholipid standards (Supelco, Bellfontaine, PA) were cochromatographed on each chromatography plate. Inorganic phosphorus was measured by the technique of Bartlett (1) on silica scraped from identified phospholipid spots visualized by brief exposure to iodine vapors. Disaturated phosphatidylcholine was determined using the technique of Mason et al. (22) on phosphatidylcholine separated on initial chromatography.

Protein and albumin determinations. Protein concentration in effluent was measured by the method of Lowry and co-workers (21) using crystalline bovine serum albumin (Sigma Chemical Co., St. Louis, MO) as a standard. Albumin content was determined in effluent using goat anti-guinea pig albumin antibody (Cappell Laboratory, Cochranvile, PA) by rocket immunoelectrophoresis by comparing peak heights to a standard curve created with guinea pig albumin.

Histology. Guinea pig lungs were fixed in vivo at $15 \mathrm{~cm}$ of $10 \%$ formalin pressure through the endotracheal tube for $48 \mathrm{~h}$ after the animal had been exsanguinated by clipping the abdominal aorta. Hematoxylin and eosin-stained $5-\mu \mathrm{m}$ sections of lung were elevated under light microscopy for parenchymal changes using an ocular grid.

Patient data. Patient data was tabulated retrospectively and radiographic diagnosis reviewed with a pediatric radiologist.

Statistical analysis. The student $t$ test was used to compare the differences between mean values for the cell populations, chemotactic indices, and elastase activities in these experiments. Differences in proportions of phospholipids were compared by chisquare analysis.

\section{RESULTS}

Cell populations. There were no differences in the conditions of exposure of each group of animals except for the oxygen environment. Weight loss $(2.1 \pm 0.8 \mathrm{~g})$ in oxygen-exposed guinea pig pups was greater $(P<0.05)$ over the first $72 \mathrm{~h}$ of life than in air-reared $(0.8 \pm 0.55 \mathrm{~g})$ animals. One pup undergoing oxygen exposure died at $130 \mathrm{~h}$ with pulmonary congestion. Visible tachypnea was present in all pups remaining in $\mathrm{FiO}_{2}>0.9$ for $144 \mathrm{~h}$.

Neonatal guinea pig lung lavage cell populations are presented

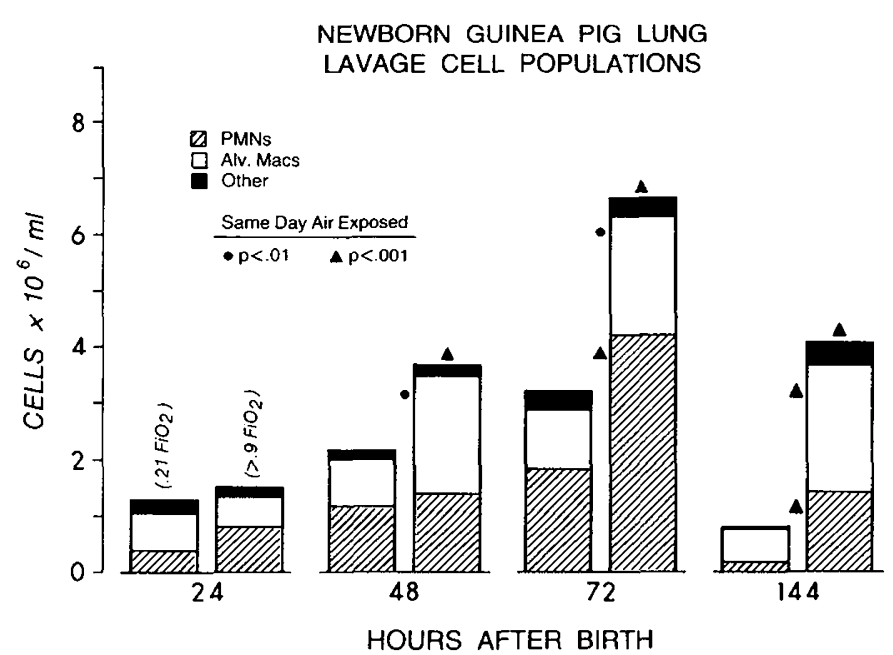

Fig. 2. Lung lavage cell populations for oxygen-exposed guinea pigs are presented for age-matched air-exposed newborn guinea pigs. By $48 \mathrm{~h}$ of oxygen exposure, total cell number exceeded air-exposed animals and alveolar macrophages exceeded guinea pigs in an air environment. These changes were more evident at $72 \mathrm{~h}$. By $144 \mathrm{~h}$, total cell number and the proportion of alveolar macrophages and polymorphonuclear leukocytes also exceeded air exposed animals. The "other" category refers to other cell types identified by cytology. These were primary mononuclear cells. in Figure 2. By $48 \mathrm{~h}$ of oxygen exposure, total lung lavage cell populations were significantly greater and the proportion of alveolar macrophages were larger than for age-matched, air-exposed neonates. By $72 \mathrm{~h}$, the total cell number and proportion of alveolar macrophages and polymorphonuclear leukocytes were significantly greater than age-matched, air-exposed pups. By $144 \mathrm{~h}$ of life, the total number of cells found in lung lavage had declined in both groups; yet the oxygen-exposed pups still had a greater number of cells and greater proportions of both inflammatory cell types. Other cell types, primarily monocytes, were found also to be significantly greater than in air-reared guinea pigs after $144 \mathrm{~h}$ of $\mathrm{FiO}_{2}>0.9$ exposure.

Chemotactic response of phagocytic cells. Directed migration of inflammatory cells obtained by lung lavage from oxygen- and airexposed newborn guinea pigs are illustrated in Figure 3. Expressed as \% of the chemotactic index, alveolar macrophage chemotaxis to $1 \times 10^{-5} \mathrm{~N}$-formyl-methionyl phenylalanine, an optimal chemotactic concentration for this peptide, in oxygen-exposed guinea pig neonates exceeded air-exposed neonates for the entire duration of the experiment. Chemotaxis of polymorphonuclear leukocytes declined to below control values by $72 \mathrm{~h}$; however, between 72 and 144 hours of $\mathrm{FiO}_{2}>0.9$ exposure, there was a 6-fold increase in polymorphonuclear leukocyte chemotaxis to this chemotactic peptide.

To determine whether endogenous chemoattractants were present in the lung with varying durations of oxygen exposure, inflammatory cells from air-exposed guinea pig neonates were exposed to lung lavage supernatant from air- and oxygen-exposed neonates (Table 1), using the same methodology. Compared to lung lavage supernatant from air-exposed guinea pig neonates, lung lavage supernatant from 72-144 h oxygen-exposed animals evoked a 15-30-fold greater chemotactic response for air exposed lung lavage polymorphonuclear leukocytes. Alveolar macrophage chemotaxis increased 10- and 20-fold, respectively, under similar exposure conditions. Random and activated random migration to chemotactic peptides for both inflammatory cell types remained relatively constant using cells from air-exposed neonates and in cross-over studies performed on cells from oxygen-exposed animals.

CHEMOTACTIC RESPONSE OF LUNG LAVAGE ALVEOLAR MACROPHAGES OR PMNS

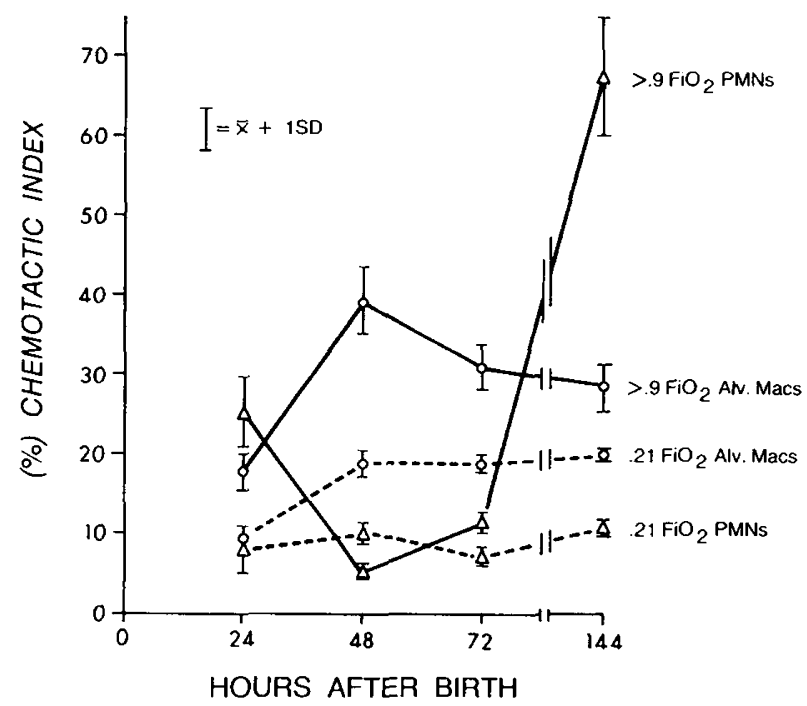

Fig. 3. Chemotactic response of guinea pig alveolar macrophages and polymorphonuclear neutrophils to $1 \times 10^{-5} \mathrm{M}$ FMP. Alveolar macrophages $(\mathrm{O})$ from newborn guinea pigs exposed to $\mathrm{FiO}_{2}>0.9$ are more chemotactic at each postnatal age than air-exposed neonates. Although initially depressed in directed migration behavior, polymorphonuclear neutrophils $(\Delta)$ from $\mathrm{Fio}_{2}>0.9$ animals were significantly more chemotactic to $1 \times 10^{-5}$ M FMP by $144 \mathrm{~h}$. Data presented as mean \pm 1 S.D. chemotactic index for each postnatal period. 
Elastase activity. Total elastase activity in $100 \mu \mathrm{l}$ of lung effluent supernatant is present in Figure 4. Total elastase activity was significantly greater in effluent from air-exposed guinea pig neonates for the first $72 \mathrm{~h}$ of life. Control total elastase activity, however, declined although animals exposed to oxygen had increases in elastolytic activity over $72 \mathrm{~h}$ that remained nearly constant by $144 \mathrm{~h}$ of oxygen exposure. Metalloelastase activity, however, rose nearly 20 -fold over 3 days of oxygen exposure and significantly exceeded metalloelastase activity found in air-exposed neonatal animals. This rise in metalloelastase activity occurred concomitantly with the absolute increase in inflammatory cell population found on day 3 of life and appears to be related to the significant increase in alveolar macrophages found in oxygenexposed neonatal guinea pigs. Serine protease activity followed the pattern of total elastase activity. The sum of metalloelastase and serine elastase activity was found to be $96.8 \pm 11.3 \%$ of the total elastase measured before selective inhibition.

Phospholipids. In air- and oxygen-exposed neonatal guinea pigs, daily comparisons of lung lavage phospholipids did not reveal any significant differences in phosphatidylcholine, sphingomyelin, phosphatidylglycerol, or phosphatidylserine plus phosphatidylethanolamine composition. At $48 \mathrm{~h}$ the \% of lung lavage phosphati-

Table 1. Chemotactic index of polymorphonuclear leukocytes and alveolar macrophages from $0.21 \mathrm{FiO}_{2}$ exposed newborn guinea

\begin{tabular}{|c|c|c|}
\hline Chemotactic agent & $\begin{array}{l}\text { Polymorphonuclear } \\
\text { leukocytes } \\
(\%)\end{array}$ & $\begin{array}{c}\text { Alveolar } \\
\text { macrophages } \\
(\%)\end{array}$ \\
\hline $\mathrm{BGSS}+2 \% \mathrm{BSA}$ (random) & $1.2 \pm 0.7$ & $0.5 \pm 0.2$ \\
\hline $\begin{array}{c}1 \times 10^{-5} \text { M FMP (active ran- } \\
\text { dom) in GBSS }+2 \% \text { BSA }\end{array}$ & $7.6 \pm 2.3$ & $9.2 \pm 4.1$ \\
\hline $\begin{array}{l}\text { Lung lavage supernatant } \\
\text { from air-exposed guinea } \\
\text { pig }\end{array}$ & $2.1 \pm 1.1$ & $1.5 \pm 0.4$ \\
\hline $\begin{array}{l}\text { Lung lavage supernatant } \\
\text { from } 72 \mathrm{~h}>0.9 \mathrm{Fio}_{2} \text { ex- } \\
\text { posed guinea pig }\end{array}$ & $33.1 \pm 7.4^{3}$ & $11.5 \pm 2.4^{2}$ \\
\hline $\begin{array}{l}\text { Lung lavage supernatant } \\
\text { from } 144 \mathrm{~h}>0.9 \mathrm{FiO}_{2} \text { ex- } \\
\text { posed guinea pig }\end{array}$ & $67.5 \pm 15.2^{3}$ & $20.8 \pm 6.1^{3}$ \\
\hline
\end{tabular}

' Chemotactic index of polymorphonuclear neutrophils and alveolar macrophages obtained from 1-day-old air-exposed neonates exposed to gradients of GBSS $+2 \% \mathrm{BSA}$ in upper and lower chambers for random migration, $1 \times 10^{-5} \mathrm{~N}$-formyl-methionyl phenyalanine in GBSS $+2 \%$ BSA for active random migration. Cells were then exposed to lung lavage supernatant from air-exposed and oxygen-exposed neonatal guinea pigs.

$$
\begin{aligned}
& { }^{2} P<0.1 . \\
& { }^{3} P<0.001 .
\end{aligned}
$$

dylinositol was significantly less in the oxygen-exposed neonatal guinea pigs. Disaturated phosphatidylcholine increased over 2fold in the oxygen-exposed neonatal guinea pigs by day 3 and significantly exceeded in \% composition, the disaturated phosphatidylcholine found in air-exposed controls (Table 2).

Protein and albumin. Lung lavage supernatant total protein and albumin was unchanged in the air-exposed neonatal animals for $144 \mathrm{~h}$. Owing to the well described effects of high oxygen exposure on vascular permeability, the total protein and albumin content per $\mathrm{ml}$ of supernatant is illustrated in Figure 5 . Within $48 \mathrm{~h}$ of oxygen exposure, the levels of both total protein and albumin exceeded values found in air-exposed neonates. By $144 \mathrm{~h}$, the rise in lung lavage supernatant total protein was nearly paralleled by the rise in albumin suggesting that the observed increases in lung lavage protein were derived from transudation of serum proteins.

Histology. Light microscopy of representative lung sections in oxygen-exposed animals revealed thickened edematous alveolar septa, inflammatory cell infiltration into the alveolar spaces with alveolar macrophage predominance, focal atelectasis, and areas of pulmonary hemorrhage. No evidence of pulmonary pathology was evident in control animals.

Patient samples. Lung effluent from 12 neonates requiring en-

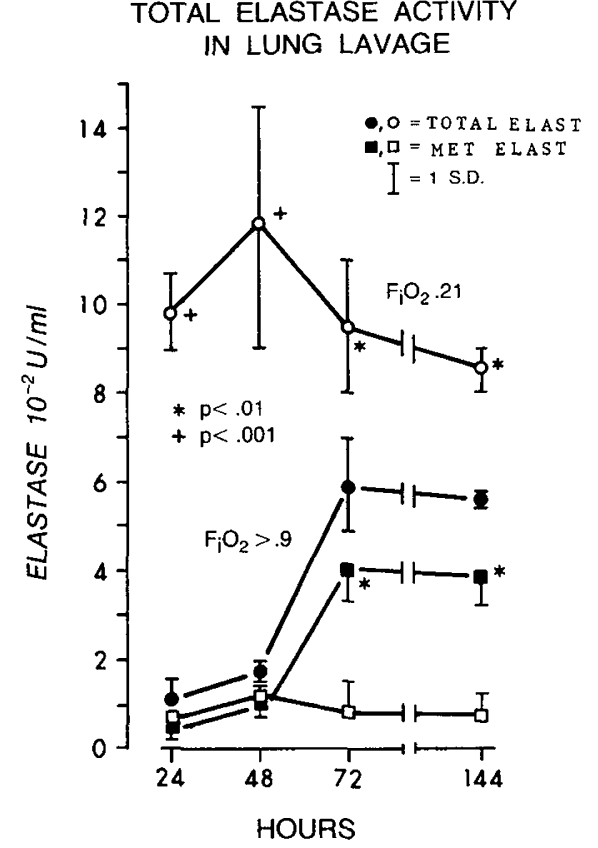

Fig. 4. Total elastase activity for $\mathrm{FiO}_{2}>0.9(\bullet)$ and room air $(\mathrm{O})$ for each postnatal period. Metalloelastase in $\mathrm{Fio}_{2}>0.9$ exposed guinea pigs $(\square)$ is significantly higher than in the air exposed $(\square)$ guinea pigs.

\begin{tabular}{|c|c|c|c|c|c|c|c|c|}
\hline \multirow[b]{2}{*}{ Lipid } & \multicolumn{2}{|c|}{$24 \mathrm{~h}$ of life } & \multicolumn{2}{|c|}{$48 \mathrm{~h}$ of life } & \multicolumn{2}{|c|}{$72 \mathrm{~h}$ of life } & \multicolumn{2}{|c|}{$144 \mathrm{~h}$ of life } \\
\hline & Air & $\mathrm{O}_{2}$ & Air & $\mathrm{O}_{2}$ & Air & $\mathrm{O}_{2}$ & Air & $\mathrm{O}_{2}$ \\
\hline Sph & $8.9 \pm 2.2$ & $14.6 \pm 1.3$ & $9.5 \pm 2.3$ & $9.1 \pm 1.3$ & $6.2 \pm .75$ & 10.2 & $4.8 \pm 1.2$ & $3.7 \pm .56$ \\
\hline $\mathrm{PC}$ & $63.8 \pm 4.3$ & $58.8 \pm 5.5$ & $63.6 \pm 13.9$ & $79.0 \pm 2.8$ & $84.0 \pm 4.6$ & $73.6 \pm .5$ & $82.3 \pm 2.6$ & $79.3 \pm .64$ \\
\hline PI & $11.8 \pm 2.2$ & $12.7 \pm 8.0$ & $15.6 \pm 7.8^{2}$ & $6.0 \pm 1.7$ & $4.27 \pm 4.8$ & $6.6 \pm 2.6$ & $2.5 \pm 1.3$ & $7.6 \pm 1.3^{2}$ \\
\hline PG & $10.9 \pm 0.3$ & $8.4 \pm 1.2$ & $4.7 \pm 1.8$ & $3.5 \pm 0.3$ & $5.2 \pm 2.5$ & $3.8 \pm 2.8$ & $7.1 \pm 1.3$ & $4.6 \pm 0.42$ \\
\hline $\mathrm{PS}+\mathrm{PE}$ & $4.4 \pm .29$ & $5.4 \pm 1.9$ & $6.5 \pm 4.3$ & $2.6 \pm 0.6$ & $2.8 \pm 0.8$ & $5.7 \pm 3.8$ & $3.2 \pm 1.2$ & $4.7 \pm 0.5$ \\
\hline $\mathrm{DSPC} / \mathrm{PC}^{4}$ & $34.7 \pm 7.1$ & $37.1 \pm 6.3$ & $44.6 \pm 8.2$ & $56.9 \pm 11.2$ & $50.3 \pm 9.4$ & $64.3 \pm 7.1^{2}$ & $52.1 \pm 12.1$ & $71.7 \pm 8.9^{2}$ \\
\hline
\end{tabular}

Table 2. Distribution ${ }^{3}$ of sphingomyelin and phospholipids in guinea pig lung lavage ${ }^{\mathrm{I}}$

\footnotetext{
'Lung lavage sphingomyelin and phospholipids at $24,48,72$ and $144 \mathrm{~h}$ of air or $\mathrm{Fio}_{2}>0.9$ exposure. Sph, sphingomyelin; PC, phosphatidylcholine;
} PI, phosphatidylinositol; PG, phosphatidylglycerol; and PS + PE, the sums of phosphatidylserine and phosphatidylethanolamine. DSPC/PC, disaturated phosphatidylcholine compared to total phosphatidylcholine as \%. Note increased DSPC at 72 and $144 \mathrm{~h}$ when compared to age-matched air-exposed neonates.

${ }^{2} \chi^{2}=<0.05$ compared to same phospholipid for age-matched guinea pigs.

${ }^{3}$ Expressed as \% phospholipid phosphorus.

${ }^{4}$ Expressed as \% DSPC to total PC. 
dotracheal intubation for ventilatory failure or for surgery were obtained (Table 3). Tracheobronchial aspirate elastase in these infants is presented in Figure 5. In four infants with neonatal respiratory distress syndrome, elastase levels rose over the first 34 days but declined to less than $10^{-3} \mathrm{U}$ (Fig. 6) during the second

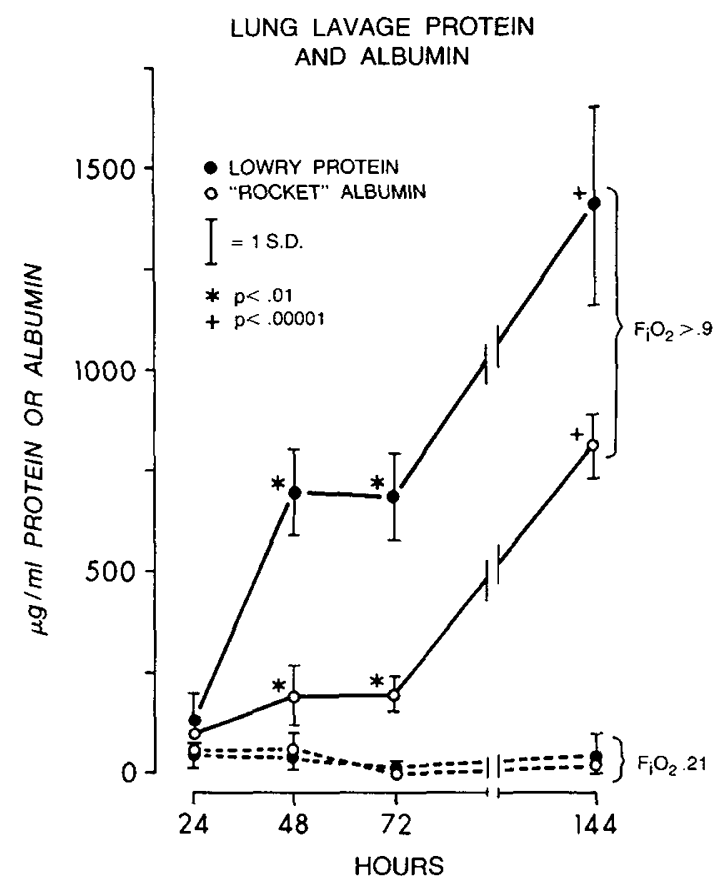

Fig. 5. Lung lavage protein and albumin is presented for each postnatal period for $\mathrm{FiO}_{2}>0.9$ and air-exposed guinea pig neonates. Total alkali soluble protein $(O)$ and albumin $(O)$ is significantly elevated over controls at 48,72 , and $144 \mathrm{~h}$ of life. Lung lavage total protein and albumin concentration remain relatively constant over the first $144 \mathrm{~h}$ of life. wk of life (patient 4 died on day 8 ). Five patients with respiratory distress syndrome continued to require mechanical ventilation. In these infants elastase activity remained $10^{-3} \mathrm{U}$ during the first 2 wk (Fig. 6, 7, 8). Elastase activity remained elevated and signifi-

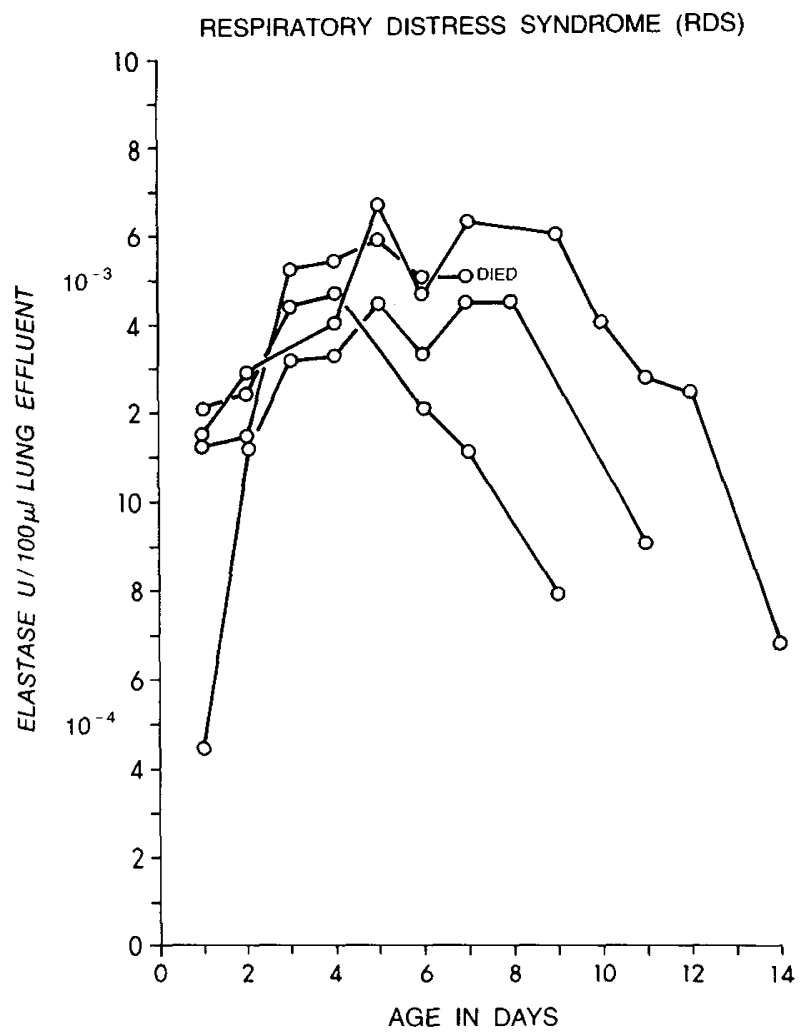

Fig. 6. Total elastase activity in lung effluent from a group of infants with respiratory distress syndrome.

Table 3. Patient characteristics of three groups with lung effluent elastase (see also figures 6, 7, and $8^{1}$

\begin{tabular}{|c|c|c|c|c|c|c|c|c|}
\hline Pt. No. & $\begin{array}{l}\text { Weight } \\
\text { (g) }\end{array}$ & $\begin{array}{l}\text { Gestational age } \\
\text { (wk) }\end{array}$ & Sepsis & $\begin{array}{l}\text { Duration of } \\
\text { IMV (hr) }\end{array}$ & $\begin{array}{c}\text { Hours } \\
\text { Fio }_{2}>0.4\end{array}$ & Airleak & & BPD \\
\hline \multicolumn{9}{|c|}{ Respiratory Distress Syndrome (RDS) } \\
\hline 1 & 2006 & 34 & $\Theta$ & 264 & 71 & Pneumothorax & & $\ominus^{2}$ \\
\hline 2 & 1475 & 33 & $\Theta$ & 169 & 60 & $\Theta$ & & $\odot$ \\
\hline 3 & 950 & 26 & $\Theta$ & 340 & 91 & Interstitial air & & $\Theta$ \\
\hline 4 & 710 & 26 & $\Theta$ & 171 & 31 & $\odot$ & & $\ominus$ \\
\hline \multicolumn{9}{|c|}{ RDS plus bronchopulmonary dysplasia (BPD) } \\
\hline 5 & 1200 & 32 & $\Theta$ & 448 & 134 & Pneumothorax & & $\oplus^{3}$ \\
\hline 6 & 880 & 26 & $\Theta$ & 361 & 184 & Interstitial air & & $\oplus$ \\
\hline 7 & 1000 & 28 & $\Theta$ & 984 & 417 & $\begin{array}{l}\text { Pneumothorax } \\
\text { Interstitial air }\end{array}$ & & $\oplus$ \\
\hline 8 & 810 & 28 & $\Theta$ & 611 & 215 & Interstitial air & & $\oplus$ \\
\hline 9 & 1260 & 29 & $\oplus$ & $>2808$ & $>2564$ & $\begin{array}{l}\text { Pneumothorax } \\
\text { Interstitial air }\end{array}$ & & $\oplus$ \\
\hline \multicolumn{9}{|c|}{ No primary lung disease } \\
\hline Pt. No. & Diagnosis & $\begin{array}{l}\text { Weight } \\
\text { (g) }\end{array}$ & $\begin{array}{l}\text { Gestational age } \\
\text { (wk) }\end{array}$ & Sepsis & $\begin{array}{l}\text { Duration of } \\
\operatorname{IMV}(\mathrm{h})\end{array}$ & $\begin{array}{c}\text { Hours } \\
\mathrm{FiO}_{2}>0.4\end{array}$ & Airleak & BPD \\
\hline 10 & Werdnig-Hoffmann & 2000 & 37 & $\Theta$ & 610 & 71 & $\ominus$ & $\ominus$ \\
\hline 11 & Gastroschesis & 2200 & 37 & $\oplus$ & 145 & 2 & $\odot$ & $\Theta$ \\
\hline 12 & $\begin{array}{l}\text { Left hemidiaphragm } \\
\text { paralysis }\end{array}$ & 1880 & 35 & $\Theta$ & 67 & 11 & $\oplus$ & $\Theta$ \\
\hline
\end{tabular}

\footnotetext{
'Weight at birth and gestational age are presented for all groups. One infant developing bronchopulmonary dysplasia and one infant without primary lung disease had positive blood cultures. Duration in hr of intermittent mandatory ventilation (IMV) and exposure to $\mathrm{FiO}_{2}>0.4$ is higher in infants developing bronchopulmonary dysplasia and in the infant with Werdnig-Hoffman syndrome. All infants developing bronchopulmonary dysplasia had one or more airleaks.

${ }^{2} \Theta$, no.

${ }^{3} \oplus$, yes.
} 
RDS + BRONCHO PULMONARY DYSPLASIA

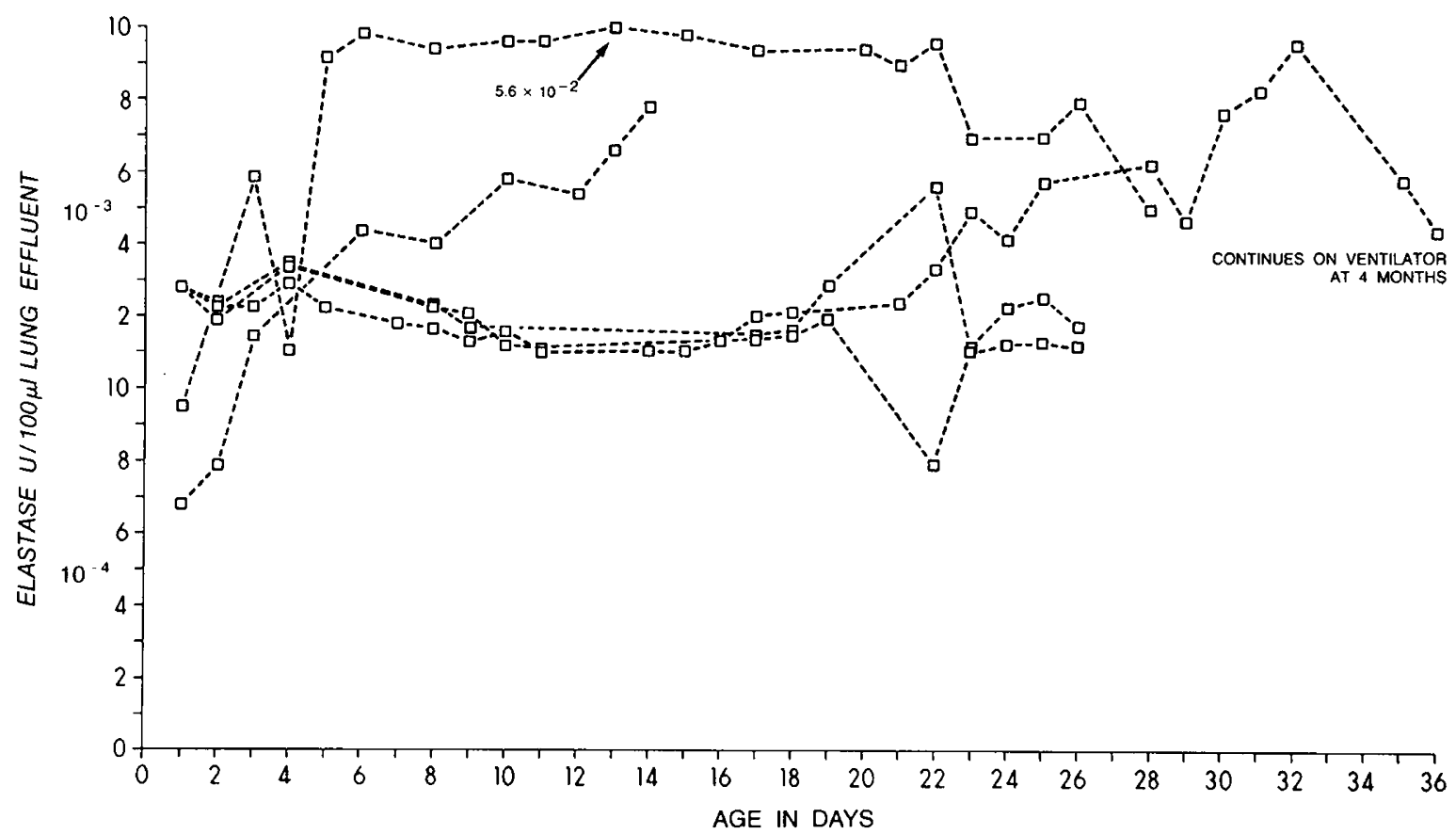

Fig. 7. Total elastase activity in lung effluent from infants whose respiratory distress syndrome was complicated by development of bronchopulmonary dysplasia.

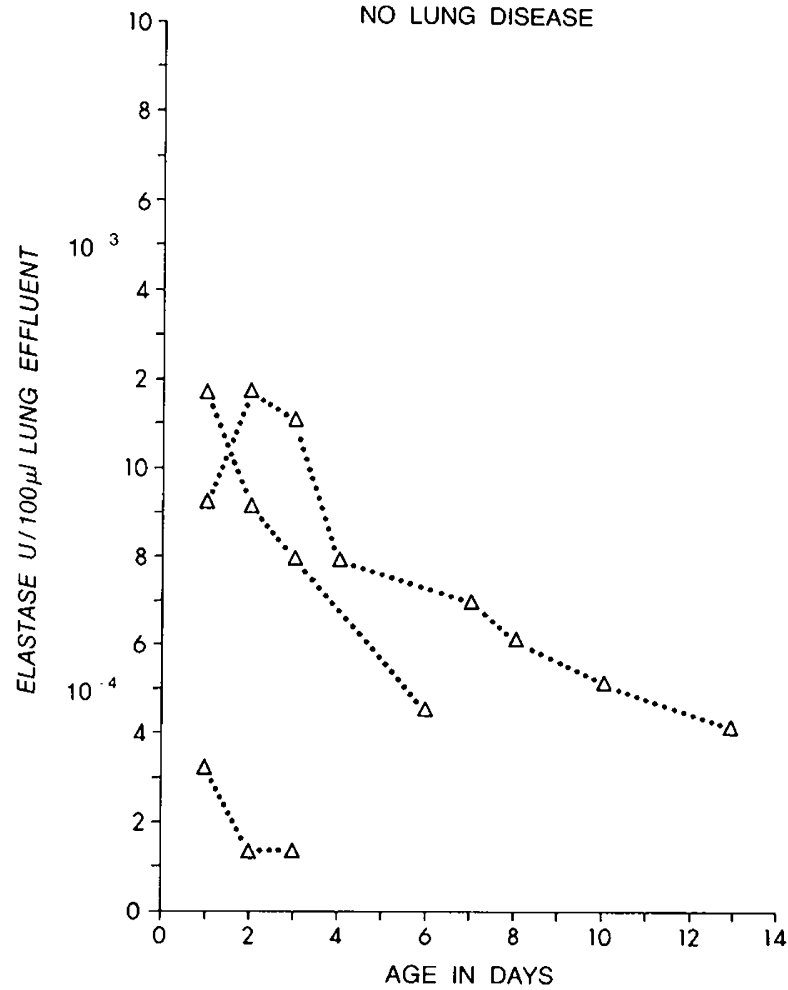

Fig. 8. Three infants who required endotracheal intubation for nonpulmonary diseases or for surgery. Elastase levels in these infants represent "reference" levels for infants without primary lung disease.

cantly higher than in infants with resolving respiratory distress syndrome by day 7 and during the second wk of life for the duration of their mechanical ventilation or until serial lung aspirates were discontinued. Figure 8 illustrates lung effluent elastase levels in infants without primary lung disease who required mechanical ventilation for comparison. Except for day 1, lung effluent elastase levels were lower than in infants with lung disease.
We found that $64 \pm 7 \%$ of the volume of fluid instilled into the lung for pulmonary toilet was recovered by endotracheal tube aspiration; in addition to $0.71 \pm 0.22 \mathrm{ml}$ (mean \pm 1 S.D.) of lung fluid suggesting a relative homogenous volume of lung effluent being aspirated using the technique employed.

\section{DISCUSSION}

The precise causes of the pathophysiologic events that culminate in neonatal chronic lung disease are unknown. Sequential cytologic examinations of tracheobronchial secretions have revealed a predominance of polymorphonuclear leukocytes (PMNs) during the first 6 days associated with exfoliation of respiratory epithelia that has been described in both oxygen toxicity and after mechanical ventilation. Thereafter, alveolar macrophages become the predominant inflammatory cell type found in lung effluent. Concomitantly there is evidence of regeneration of respiratory columnar epithelia as evidenced by nuclear chromatin changes indicative of cell renewal of metaplastic changes in infants developing chronic lung disease. This inflammatory cell predominance, in the absence of infection, suggests that alveolar macrophages and polymorphonuclear leukocytes with their proteolytic potential may be mediators of lung injury resulting in lung parenchymal fibrosis $(24,25)$. Fox and co-workers (11) found in adult rats exposed to elevated oxygen tensions for $66 \mathrm{~h}$ that pulmonary macrophages release low moelcular weight chemotaxins that induce polymorphonuclear leukocytes to release toxic oxygen radicals or proteolytic enzymes injurious to lung connective tissue. Neutropenia induced with nitrogen mustard was shown to spare the lungs of oxygen-exposed adult rats to the effects described in control animals (28), suggesting that neutrophil mediated events caused these lesions in the adult animal. Lee et al. (19) found elevated levels of neutrophilic elastase in the pulmonary lavage fluid of a majority of patients with adult respiratory distress syndrome, associated with increased numbers of leukocytes in pulmonary effluent in 20 of 23 patients. These workers have suggested that serine elastase proteolysis is the mechanism involved in the pathogenesis of the adult respiratory distress syndrome.

Janoff et al. (16) reported in adult rats that influx of PMNs into 
the lungs is secondary to the release of chemotactic agents from alveolar macrophages de novo or from macrophages damaged by hyperoxia.

Lung macrophage chemotaxins for PMNs had been previously established both in vitro and in vivo. Studies using cultured alveolar macrophages have demonstrated secretion of factors into culture media that yield a maximal response to leukocytes and lymphocytes at $24 \mathrm{~h}(5)$; however, the characteristics of the chemotaxin were not defined. Hunninghake et al. (15) have reported that partially purified chemotaxin obtained from cultured macrophages produces an outpouring of neutrophils in the lung after intratracheal instillation. Kazmierowski et al. (18) have identified a low molecular weight neutrophil chemotaxin in bronchial lavage fluid from primates who have undergone repetitive lavage. These effects appear to be related to macrophage activation rather than enhanced macrophage chemotaxis; however, Bowles et al. (5) found in adult guinea pigs that the macrophages obtained by lung lavage had a significant decrease in chemotaxin to FMP when the cells were incubated for $3 \mathrm{~h}$ in $\mathrm{Po}_{2}$ between 4l0-425 torr compared to controls. These workers hypothesized that profound hyperoxia may injure macrophage cytoskeletal apparatus, impair metabolic pathways involved in cell motility, or have alterations in the membrane receptor for FMP peptides leading to an impairment of the transduction of chemotactic signals. Our findings concur with observations by Fox et al. and Hunninghake et al. but differ from Bowles et al. In our experiments, neonatal lung macrophage exposure to hyperoxia occurred in vivo and exposure durations to oxygen were up to $144 \mathrm{~h}$. Both the duration of exposure and the in vivo environment may have altered the behavior of these cell types. In our experiment, although PMN leukocyte chemotaxis was initially impaired in lungs of animals exposed to oxygen, by $72-144 \mathrm{~h}$ there was a dramatic rise in PMN directed migration to both FMP and lung lavage supernatant most likely secondary to oxygen-induced PMN activation and macrophage-derived chemotaxins. That lung lavage supernatant from 72 and $144 \mathrm{~h}$ oxygenexposed animals substantially increased the chemotactic index of cells from air-exposed animals suggests that macrophage derived chemotaxins are the most potent mediator of directed migration.

In the neonatal guinea pig lung, although polymorphonuclear leukocytes were abundant, PMN-derived serine elastase was less than $30 \%$ of the total elastase activity as determined by PMSF inhibition, measured in oxygen-exposed animals whereas metalloprotease activity exceeded control values by $72 \mathrm{~h}$ of oxygen exposure. The leakage of serum proteins, including albumin and other serum protein components including $\alpha_{1}$ antiprotease known to inactivate the serine elastase, was found in this and other (3) studies; however, $\alpha_{1}$ antiprotease is only minimally effective in neutralizing metalloelastase activity. This suggests that in the neonatal animal, lung proteolysis results from metalloelastase protease.

Many factors may inactivate $\alpha_{\mathrm{I}}$ antiprotease including cigarette smoke $(16,17,12)$ and oxidant species generated by leukocytes during phagocytosis (6). The preterm human neonate with respiratory distress syndrome has been found to have lower levels of $\alpha_{1}$ antitrypsin in cord blood and serum within $48 \mathrm{~h}$ of birth than in gestationally matched controls without this disorder (23). The level of $\alpha_{1}$ antiprotease protecting the lung from proteolysis in these infants or in infants with prolonged oxygen therapy may be substantially less than in infants without respiratory disease. Sustained high proteolytic levels may indicate existing antiprotease activity is insufficient. This observation is similar to that found in adults with adult respiratory distress syndrome. The accumulation of PMNs found in tracheobronchial secretions of oxygen-exposed, mechanically ventilated infants may further reduce the protective effect of $\alpha_{1}$ antiprotease in the neonate by the generation of superoxide radicals or hydrogen peroxide, as well as by other proteolytic actions in addition to the effects of the elastase.

Our data are consistent with the hypothesis that neonatal oxygen exposure to $\mathrm{FiO}_{2}>0.9$ results in a lung inflammatory response characterized by macrophage and PMN recruitment into the airways capable of generation of proteases and other oxidizing species that may overwhelm the protective effects of antiproteases found in the neonatal lung. Further investigation of the magnitude of this response to various levels of oxygen exposure, the effects of mechanical ventilation, and whether supplementation of antiprotease activity in the human neonate or an animal model would alter the pathogenesis of neonatal lung injury requires further research.

\section{REFERENCES AND NOTES}

1. Bartlett, G. R.: Phosphorus assay in column chromatography. J. Biol. Chem., 234: 466 (1959).

2. Baumstark, J. S.: Studies on the elastase-serum protein interaction. I. Molecular identity of the inhibitors in human serum and direct demonstration of inhibitorelastase complexes by zone and immunoelectrophoresis. Arch. Biochem. Biophys., 118: 681 (1967)

3. Baumstark, J. S., Lee, C. T., and Luby, R. J.: Rapid inactivation of antiprotease inhibitor ( $\alpha_{1}$ antitrypsin) by elastase. Biochem. Biophys. Acta., 482: 400 (1977)

4. Bonikos, D. S., Bensch, K. G., Northway, W. M., and Edwards, D. K.: Bronchopulmonary dysplasia: the pulmonary pathologic sequel of necrotizing bronchiolitis and pulmonary fibrosis. Hum. Path., 7: 643 (1976).

5. Bowles, A. L., Dauber, J. H., and Daniele, R. P.: The effect of hyperoxia on migration of alveolar macrophages in vitro. Am. Rev. Respir. Dis., 120: 541 (1979).

6. Carp, J. and Janoff, A.: In vitro suppression of serum elastase-inhibitory capacity by reactive oxygen species generated by phagocytosing polymorphonuclear leukocytes. J. Clin. Invest., 63: 793 (1979)

7. Dauber, J. H. and Daniele, R. P.: Secretion of chemotaxins by guinea pig lung macrophages. I. The spectrum of inflammatory cell responses. Exp. Lung Res. l: 23 (1980).

8. Dauber, J. H. and Daniele, R. P.: Chemotactic activity of guinea pig alveolar macrophages. Am. Rev. Respir. Dis., 117: 673 (1981).

9. Fahrey, D. E. and Gold, A. M.: Sulfonyl fluorides as inhibitors of esterases. I. Rates of reaction with acetylcholinesterase, K-chymotrypsin and trypsin. J Am. Chem. Soc., 85: 997 (1963).

10. Folch, J., Lees, M., and Sloane-Stanley, G. H.: A simple method for the isolation and purification of total lipids from animal tissues. J. Biol. Chem., 226: 497 (1957)

11. Fox, R. B., Hoidal, J. R., Brown, D. M., and Repine, J. E.: Hyperoxia causes a preterminal influx of polymorphonuclear leukocytes (PMN) into the lungs and is associated with increased lung lavage chemotaxin (CTX) for PMN and death of alveolar macrophages (AM). Am. Rev. Respir. Dis., 122: 340 (1980).

12. Gadek, J. E., Fells, G. A., and Crystal, R. G.: Cigarette smoking induces functional antiprotease deficiency in the lower respiratory tract of humans. Science, 206: 1315 (1979).

13. Hallman, M., Kulovich, M., Kirkpatrick, E., Sugarman, R. G., and Gluck, L. Phosphatidylinositol and phosphatidylglycerol in amniotic fluid: indices of lung maturity. Amer. J. Obs. Gynecol., 125: 613 (1976).

14. Hinman, L. M., Stevens, C. A., Matthay, R. A., and Gee, J. B. L.: Elastase and lysozyme activities in human alveolar macrophages: effects of cigarette smok ing. Am. Rev, Respir. Dis., 121: 263 (1980).

15. Hunninghake, G. W., Gallin, J. I., and Fauci, A. S.: Immunologic reactivity of the lung. The in vivo and in vitro generation of a neutrophil chemotactic factor by alveolar macrophages. Am. Rev. Respir. Dis., 117: 15 (1978).

16. Janoff, A., White, R., Carp, H., Harel, S., Dearing, R., and Lee, D.: Lung injury induced by leucocytic proteases. Am. J. Path., 97: 111 (1979).

17. Janoff, A., Carp, H., Lee, D. K., and Drew, R. T.: Cigarette smoke inhalation decreases $\alpha_{1}$ antitrypsin activity in rat lung. Science, 206: 1313 (1979).

18. Kazmierowski, J. A., Gallin, J. I., and Reynold, H. Y.: Mechanism for the inflammatory response in primate lungs. J. Clin. Invest., 59: 273 (1973).

19. Lee, C. T., Fein, A. M., Lippmann, M., Holtzman, H., Kimbel, P., and Weinbaum, G.: Elastolytic activity in pulmonary lavage fluid from patients with adult respiratory distress syndrome. N. Engl. J. Med., 304: 192 (1981).

20. Levine, E. A., Senior, R. M., and Butler, J. V.: The elastase activity of alveolar macrophages: measurements using synthetic substrates and elastin. Am. Rev. Respir. Dis., 113: 24 (1976).

21. Lowry, O. H., Rosebrough, N. J., and Farr, A. L.: Protein measurement with the folin phenol reagent. J. Biol. Chem., 193: 265 (195 I).

22. Mason, R. J., Nellenbogen, J., and Clements, J. A.: Isolation of disaturated phosphatidylcholine with osmium tetroxide. J. Lipid Res., 17: 281 (1976).

23. Mathis, R. K., Frier, C. E., Hunt, C. E., Krivit, W., and Sharp, H. L.: Alpha antitrypsin in the respiratory distress syndrome. N. Engl. J. Med., 288: 59 (1973).

24. Merritt, T. A., Puccia, J., and Stuard, I. D.: Cytologic evaluation of pulmonary effluent in neonates with respiratory distress syndrome and bronchopulmonary dysplasia. Acta Cytol., 25: 631 (1981)

25. Merritt, T. A., Stuard, I. D., Puccia, J., Edwards, D. K., Wood, B., Finkelstein, J., and Shapiro, D.: Newborn tracheal aspirate cytology: classification during respiratory distress syndrome and bronchopulmonary dysplasia. J. Pediatr., 98: 949 (1981).

26. Northway, W. J., Rosan, R. C., and Porter, D. Y.: Pulmonary disease following respirator therapy of hyaline-membrane disease: bronchopulmonary dysplasia. N. Engl. J. Med., 267: 357 (1967).

27. Northway, W. J., Rosan, R. C., Shininian, L., Castellino, R. A., Gyepes, M. T and Durbridge, T.: Radiologic and histologic investigation of pulmonary oxygen toxicity in newborn guinea pigs. Invest. Radiol., 4: 148 (1969). 
28. Shasby, D. M., Fox, R. B., Harada, R. N., and Repine, J. E.: Mechanisms of pulmonary oxygen toxicity: neutropenia protects against acute lung injury from hyperoxia. Am. Rev. Respir. Dis., 121: 258 (1980).

29. This research was supported by U.S. Public Health Service, HD-16292 to Dr. Merritt.

30. Reprint requests should be sent to Dr. T. Allen Merritt, Division of Neonatal/
Perinatal Medicine, Department of Pediatrics, University of California, San Diego Medical Center, 225 W. Dickinson St., San Diego, Calif., 92103.

31. I wish to thank Betty Bible, B.S.N., Jack Finkelstein, Ph.D. and Robert Lyon, $\mathrm{Ph} . \mathrm{D}$. for their assistance and suggestions.

32. Received for publication October 2, 1981 .

33. Accepted for publication February 23, 1982.

Copyright $(\mathcal{C} 1982$ International Pediatric Research Foundation, Inc. 